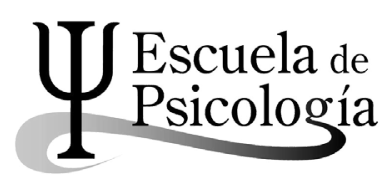

Wímb lu, Rev. electrónica de estudiantes Esc. de psicología, Univ. de Costa Rica. 10 (2): 77-91, 2015 / ISSN: 1659-2107

\title{
INDOCILIDAD DEL ELLO AL TRATAMIENTO TÓPICO: CONTINGENCIA Y LUGAR EN LA ESTRUCTURA A PARTIR DE ALGUNOS LINEAMIENTOS DE LA ÉTICA DEL ACTO
}

\author{
Intractability of the "id" to topical treatment: Contingency and place \\ in the structure and some guidelines from ethics of the act
}

Bruno Carignano*

\begin{abstract}
Resumen: El artículo se aboca a problematizar algunas concepciones del ello que se consideran centradas, demasiado ingenuamente, en lo tópico. Con este fin se examinan algunos aspectos de lo teorizado por dos autores: Jean Laplanche y André Green, en discusión con algunas directrices de Jacques Lacan para situar el lugar del ello en la estructura psíquica. El objetivo principal del artículo es el de intentar mostrar cómo las concepciones del ello con las cuales se opera no serían indiferentes en consecuencias que delinean diversas posiciones respecto a la clínica psicoanalítica. Al ponerse de relieve otro alcance que el meramente tópico para la noción de ello, se acentúa el desplazamiento del eje instancias-identificaciones al de la ética del acto; para lo cual se avanza tomando el problema de la contingencia en la estructura psíquica como primordial. Por otro lado, se procede a fundamentar la importancia que esto tiene en psicoanálisis a partir de argumentaciones del propio Freud, especialmente cuando se dedica a indagar las razones que afectan a la separación ello-yo en el tratamiento clínico del síntoma. Allí puede verse como se consigue un modo de abordaje de la articulación entre estas instancias que no es precisamente el de una tajante separación tópica y que conduce a situar a un viviente (que con Lacan podemos llamar "sujeto") que actúa como una problemática unidad escindida. La noción de responsabilidad ocupa un lugar crucial en esta argumentación, puesto que la división tópica no exime a ese viviente de asumir, desde esa multívoca instancia del yo, los efectos de la existencia del ello.
\end{abstract}

Palabras clave: Lo tópico (el ello y la escisión ello-yo), narcisismo primario, síntoma, responsabilidad, ética del acto.

Universidad Nacional de Rosario, Docente Facultad de psicología. Argentina.

Correo electrónico: brunocarignano@yahoo.com

Recepción: 25/6/2015 Aceptación: 20/7/2015 


\begin{abstract}
The paper focus on some problematics conceptions of the "id" which are considered to be naïvely restricted to the topological aspects of the psychic structure. With this aim, some aspects of the conceptions of two different authors are examined: Jean Laplanche and André Green, with the idea of discussing, from certain Jacques Lacan's guidelines, the place of the "id" in the psychic structure. The main objective of the paper is to expose the way in which the conceptions of the "id" with which the psychoanalyst works may have consequences that determines different positions regarding the clinical practice of psychoanalysis. It is considered how other aspects than the mere topological are to be highlighted concerning the "id", problem that leads to the displacement of the axis from systems-identifications to that of the ethics of the act; for which the reference to the issue of contingency in the psychic structure is extremely relevant. Besides, the importance of this issue in psychoanalysis is analysed taking into account some freudian arguments, especially the ones in which he examines the reasons that involves the split between the ego and the id in the clinical treatment of the symptom. At that point, it can be seen a particular approach not precisely linked to a categorical topological division between the systems, but related to the fact that "the subject" acts as a whole unit (which is split). The notion of responsibility occupies a crucial role, given that the topological division does not exempt the subject's assumption of the effects produced by the existence of the "id".
\end{abstract}

Key Words: The topology (the id and the id-ego splitting), primary narcissism, symptom, responsibility, ethics of the act

"No es fácil pensar al ello"

J. Lacan

"No esperéis que del ello pueda comunicaros grandes cosas. Es la parte oscura e inaccesible de nuestra personalidad [...] en su mayor parte tiene carácter negativo, no pudiendo ser descrito sino como antitético del yo. Nos aproximamos al ello por medio de analogías, designándolo como un caos o como una caldera, plena de hirvientes estímulos"

S. Freud

"Entonces.. en el lugar de lo que había definido como el ello de la gramática el Sr. Green me recordó que no tenía que olvidar la existencia del caldero"

"Con que ironía Freud podía hacer pasar tales imágenes es algo que, seguramente, habría que estudiar" J. Lacan

\title{
1. Introducción
}

En "El yo y el ello" Freud nos advierte sobre los riesgos de tomar demasiado en serio la representación tópica del aparto anímico: "Es ésta una de las dificultades que surgen cuando nos decidimos a utilizar la representación espacial, tópica, de la vida anímica" (2013a, p.2705). ¿Cuáles son esos riesgos? Aunque en este caso Freud parezca fundamentalmente remitirse a la función de la conciencia (o más precisamente del preconciente) en el pasaje de una inscripción psíquica de un sistema a otro (retomando argumentaciones de "Lo inconsciente", donde 
había conseguido esa especie de transacción entre lo tópico y lo económico para dar cuenta del problema), considero que no deja de ser un buen punto de partida para situar otros niveles de las dificultades que la representación espacial conlleva.

El que aquí me interesa especialmente se ubica en el terreno mismo de la constitución del aparato psíquico como tópica en lo que hace al lugar que allí suele otorgarse al ello. Con esto no me refiero sólo a lo que podría enfatizarse, por ejemplo desde una óptica como la de Laplanche, como una labilidad de los límites de las diferentes instancias que lo componen. Se trata de algo más fundamental: en cierto aspecto es la división tópica misma la que fracasa. Entiendo que ese punto se torna más notoriamente manifiesto en la contradicción terminológica que podría implicar hablar de una "tópica del ello". El ello, más que ser un lugar psíquico, ¿no es lo que se sustrae de una localización espacial (así sea ella virtual y no anatómica)? Intentaré mostrar que en ciertas lecturas del ello como lugar psíquico podemos vislumbrar un deslizamiento que llevaría a operar dentro de ese riesgo al que Freud se refiere. Una de las hipótesis fundamentales que sostenemos puede formularse así: encontramos allí la raíz de profundas consecuencias sobre la desestimación del lugar de la ética del acto respecto del modo de pensar el valor y la incidencia de ciertos conceptos en un psicoanálisis. Aunque a primera vista pueda parecer una extrapolación brusca, trataremos aquí de dejar expuesta la articulación.

\section{Limitaciones de ciertas lecturas del ello ingenuamente centradas en lo tópico.}

En primer lugar, comencemos considerando que el valor teórico de la "segunda tópica" no puede residir en la composición de una organización estructural del psiquismo. Recordemos que Freud promovía, al titular así su conferencia número 31, más una "descomposición de la personalidad psíquica" (1986c) que una "composición", figura antagónica que algunas lecturas parecen proponernos. La nueva tópica, en lugar de instaurar un aparato compuesto por instancias o sistemas, nos muestra la escisión en el seno mismo del psiquismo. Una escisión problemática, como lo veremos, porque implica no dejar de lado la cuestión de la unidad, de la no separación, en cierto punto, entre las diferentes instancias.

En una dirección que encuentro contraria a la perspectiva freudiana de la descomposición, Laplanche lee la diferencia entre una y otra tópica, situando como eje la noción de "mecanismo" para la primera ("la primera descripción del aparto psíquico permanecía más abstracta y más psicologizante" (1981, p.168); e impulsa la noción de "antropomorfismo" para la segunda, lo que la 
ubicaría, según él, en mayor proximidad de la experiencia clínica (Laplanche, 1981, p.167/8) ${ }^{1}$. Dejando de lado el hecho de que ese antropomorfismo ${ }^{2}$ supone caer en una versión estrictamente descriptiva de las identificaciones: "el conflicto escapa a esas dificultades de una suerte de mecanismo psíquico, para devenir conflicto entre las partes del yo que tienen su origen histórico, su voz, su carácter propio" (Laplanche, 1981, p.168), esto además implica, para lo que aquí me interesa, abordar la constitución de la tópica de una manera que lleva a soslayar totalmente como las identificaciones formadoras de las instancias deben ser atravesadas por el problema del acto para cobrar la relevancia clínica que requieren en psicoanálisis. Ello se perfila solamente si atendemos a la función que cobra la escisión en el seno de un viviente responsable, unitariamente, de lo que le sucede ${ }^{3}$ y no en autónomas fragmentaciones ${ }^{4}$ (con esto queremos decir que el conflicto no deja de ser nunca el del je - o, mejor dicho, de lo que a partir de esta noción podemos pensar respecto del lugar del sujeto -, aun cuando, por supuesto, estén implicadas las diversas instancias de la tópica). Al revés de lo que supone Laplanche, nos parece que el matiz psicologizante se introduce con su manera de leer la segunda tópica, esto es, con una versión antropomórfica de las instancias ajena a la ética del acto.

La cuestión se aclara un poco si enfatizamos, como contrapunto, la lectura antagónica que da Lacan de la Spaltung freudiana del yo en función de la división del sujeto. Ella nos muestra que la "escisión del yo" debe ser interpretada según los alcances que tiene en la estructura del sujeto, sin que deba quedar confinada a materializar sólo una herida psíquica imaginaria ${ }^{5}$. Este traspaso de registro implica que ese yo dividido se conecte con el yo del discurso, el je hablante, y no refiera sólo al moi en su dimensión imaginaria. Esta forma de entroncar al yo freudiano con el sujeto es lo que dirige el enfoque del problema hacia el plano de la articulación estructura-acto, permitiendo realzar el alcance clínico que tienen las instancias psíquicas planteadas por Freud. Me refiero precisamente al modo en que se articula "la relación je del discurso/moi como objeto, tal como funciona en la trama de discurso" (Kuri, 2010, p.54).

Por el contrario, dar una respuesta tópica a esa escisión tiene consecuencias a la hora de pensar la cuestión de la responsabilidad en psicoanálisis, promoviendo en ocasiones falaces divisiones espaciales (ajenas a la metapsicología): desde una región psíquica se es responsable, no desde la otra. Toda la cuestión reside en cómo pensamos la relación entre división y unidad en el seno de la realidad humana, a lo que volveremos más adelante. La noción freudiana de ello es mucho más rica, y prolífica en consecuencias, que aquello a que corrientemente se la reduce: un lugar psíquico, cuando para Freud era más bien un no lugar, la alteridad de un lugar. Ese valor de la noción freudiana de ello puede ser recuperado por una lectura que abra el horizonte a los problemas del acto; pues agotar la 
segunda tópica en la explicación por las operaciones formadoras de las instancias, encarando el problema como el de distintas sedes en conflicto que tendrían "voz" y " carácter propio", lleva a estrechar la clínica a una perspectiva de índole más psicológica 6 , una de cuyas versiones creemos encontrar en ese antropomorfismo al que se refiere Laplanche. Si lo que aquí sostenemos es cierto, el valor clínico de la noción de ello debe mostrarnos cuán indócil es la segunda tópica a ser reducida al mero registro de un sedimento de identificaciones formadoras.

Abordar la representación espacial del aparato anímico desde la perspectiva de la ética del acto debe producir necesariamente como efecto un descentramiento, una alteración, con lo cual llegamos a otra de las hipótesis centrales que aquí se sostienen: el sentido fundamental de la segunda tópica debe ser buscado en el entrecruzamiento de dos horizontes, el de las identificaciones y el del la ética del acto. La pregunta por las operaciones identificatorias formadoras de las instancias del aparato pasa por un carril diferente al de la pregunta clínica que instala lo que hay insoslayablemente de acto en la estructura. Por eso la brújula orientadora para arribar a situar como lo tópico no es ajeno a las determinaciones del acto, es la conocida sentencia freudiana: "Wo Es war, soll Ich werden", sentencia que tanto ha aprovechado Lacan: precisamente, para inclinar la lectura de la tópica hacia una perspectiva ética más que conceptual, desplazando el eje del problema.

Este deslizamiento de la segunda tópica hacia el plano ético lo encontramos ya tempranamente en Lacan, en el planteo con que se inicia el seminario El yo en la teoría de Freud y en la técnica psicoanalítica. Allí pone a jugar los operadores estructurales de la constitución del sujeto en el campo del Otro. Homofónicamente el Es (Das Es: el ello) es la letra "S" en francés, el sujeto. Las instancias de la nueva tópica no son los registros residuales de identificaciones que se han inscripto en el aparato como sistemas, o al menos no son sólo eso, sino las marcas del descentramiento del sujeto, vislumbrado en un yo (je) que empezó a negarse a responder. En fin, lo que interesa retener aquí es que la llamada "segunda tópica" no es independiente de los problemas implicados en la estructura del sujeto, punto que conecta lo tópico con el acto. Dejar de lado esta cuestión ha extraviado, según nuestro juicio, a determinados autores, entre los cuales destacamos a Jean Laplanche y André Green. Algunos de sus desarrollos permiten ver el precio pagado, que se manifestada en la estrechez con que formulan cuestiones clínicas en referencia a las instancias, consecuencia en parte del gesto teórico de encorsetar al ello en un lugar psíquico7. Seré breve en este punto: estas lecturas de la tópica no parecen vislumbrarnos ningún atisbo de proposición ética. En síntesis, se trata de mostrar cómo, desde ángulos opuestos de lectura, podemos ya sea soterrar tópicamente al ello (y anular así el valor teórico y clínico que aquí creemos que debe rescatarse), ya sea darle el vigor que requiere (muy presente en varias formulaciones freudianas), desde el plano de la estructura del sujeto en función de la ética del acto ${ }^{8}$. 


\section{El ello como "gran reservorio de la libido" y los problemas conceptuales del narcisismo primario. Contingencia y lugar del ello en la estructura}

Antes de avanzar, encaremos la cuestión desde otra perspectiva para intentar llegar al mismo núcleo problemático: ¿cómo entender esa afirmación freudiana de que el ello es el "gran reservorio de la libido" (Freud, [1923] (1986a), p.32)? Plantear apresuradamente que el ello sería asimilable a un cuerpo en el que todavía no se ha diferenciado la organización del yo a partir de las identificaciones y del contacto con el mundo exterior, y que de lo que se trataría en esa nueva versión del narcisismo primario promovida en "El yo y el ello" es de una especie de autoinvestidura del cuerpo por sí mismo, puede implicar un deslizamiento hacia una lectura sustancialista del ello y de las pulsiones que anula lo fecundo de la noción misma de ello. Dicho planteo se anclaría en la asimilación del ello a un lugar psíquico, donde el cuerpo adquiriría esa figura de vesícula indiferenciada de que nos habla Freud ${ }^{9}$. El esquema del nuevo aparato auspicia en ese sentido una confusión al ubicar al ello en un lugar, aunque respecto del alcance del dibujo se haya circunscrito una limitación precisa al calificarse su significación como "puramente descriptiva"10 (Freud, 2013a, p.2708).

En contra del planteo de una inicial autoinvestidura corporal del ello, que pareciera ser descriptivamente insinuada por la figura del reservorio, consideremos esta cuestión relevante para la teoría: las pulsiones no son montajes que parten del cuerpo para volver a él. (Lo que sería válido sólo si pensáramos que las pulsiones se reducen a sus fuentes corporales). Digámoslo sintéticamente: las pulsiones no tienen su origen en el propio cuerpo, su origen está perdido y es producto del engarce del cuerpo con el lenguaje operado a partir del vacío de la causa (donde se revela lo fundamental del lugar del gran Otro para definir el concepto de pulsión). Con esto no hago más que recordar mínimamente esa común topología del agujero entre cuerpo y lenguaje que señala Lacan en el seminario Los cuatro conceptos fundamentales del psicoanálisis para indicar desde qué punto debe ser cuestionada la figura descriptiva del reservorio.

Para contrarrestar una lectura sustancialista que pareciera anclarse en un ser libidinal del cuerpo llamado ello, pura positividad (que hace recordar a algunas lecturas cuestionables que, apoyándose en Lacan, postulan una especie de goce positivo en el ello, como si éste implicara un ser de goce tópicamente opuesto al deseo), es fundamental localizar el modo en que se inserta el cuerpo en relación con el gran Otro, para inferir de allí su pasividad, o lo que aquí preferimos llamar su contingencia, como indicativa de su lugar en la estructura. Esto permite dar otra dimensión a la noción de ello: el punto de anclaje estructural del cuerpo como raíz figurativa en que se inserta el ello respecto de la tópica 
es lo que permite abrir el ello hacia la perspectiva del acto. En contra de la confusión a la que podría inducir el esquema visual, son insistentes en Freud los puntos que muestran al ello como algo incaptable, sólo susceptible de ser aprehendido "en forma negativa". La noción de un narcisismo primario del ello, no restringido al yo, no podría traducirse en una autoinvestidura del ello por sí mismo (confusión económica que propicia la idea del ello como gran reservorio, la que tomada literalmente no permitiría diferenciar al ello del yo en el más llano sentido metapsicológico, al quitarle su carácter de pura alteridad para tornarlo algo "auto"). Al contrario, el ello es el punto de registro teórico que manifiesta como el cuerpo es pulsionalmente tomado en una estructura que lo precede y respecto de la cual el je deberá tomar alguna posición. Eso es lo que subrayamos al situar el lugar contingente del cuerpo en la estructura, lo que queda sepultado en numerosas lecturas sustancialistas de la segunda tópica. En otros términos, el ello no es un lugar psíquico que posea pulsiones desenfrenadas (como bien podría hacerlo creer la engañosa metáfora freudiana del caldero que sirve de apoyo a Green), sino la marca de la alteridad de un cuerpo trabajado por las pulsiones en su empalme con la demanda del Otro. Si pensamos, en lugar de responder por la tópica, cuál es el estatuto de esa escisión que el ello introduce en el cuerpo viviente que se constituye como yo, podemos salir de la encerrona que en este plano produce la división entre sistemas para darle otro alcance a la noción de ello en función de la relación estructura-acto ${ }^{11}$.

Veamos brevemente lo fundamental de los planteos de Green que nos permiten encarar los problemas de tomar demasiado en serio la representación tópica. Este psicoanalista, antiguo discípulo de Lacan, interviene, ya a partir de cierta distancia con su enseñanza, en la clase del 15 de marzo del 67 de La lógica del fantasma con el propósito de hacer una especie de balance entre dicha enseñanza y lo que pretende presentar como cierta pureza de los conceptos freudianos. El primer punto que despliega es el del ello en función de lo que considera un abuso de Lacan: el haberlo circunscrito a una estructura gramatical, pues cree que dicho tratamiento del ello excluye otra especificidad que lo define, la de ser receptáculo de los afectos. Todo es fundamentado por el autor retomando proposiciones del seminario en curso ${ }^{12}$. En su desarrollo escoge la figura freudiana del "caldero hirviente" que Lacan parodiará unas clases más adelante, no sin incrustar una torsión interesante por darle un giro a la metáfora que el mismo Green desliza al referirse al chiste del caldero prestado ${ }^{13}$ : de lo que se trata para Lacan en el triple rechazo del sujeto a quien le reclaman el caldero es de figurar la posición misma de los analistas ante el ello: por un lado, los analistas no han tomado en préstamo el caldero; por otro, "ese caldero está agujereado y prometer devolverlo intacto es algo totalmente aventurado" ([1966/7, p.409]). Como Lacan irónicamente lo señala, lo analistas se habían olvidado que ese caldero que es el ello estaba 
agujereado y estafaban al paciente al prometer devolverlo intacto. ¿Qué mejor metáfora que la del agujero en el seno mismo del ello para pensar la contingencia que lo hiende, que en definitiva no es otra sino la pasividad con la que el ello carga al cuerpo pulsional por no ser causa sui? Hay que considerar como fundamental la irrevocable pasividad del ello si queremos ser fieles a su estatuto; pasividad que es ocultada por la figura descriptiva del reservorio.

Según lo que venimos viendo, salta a la vista una especie de síntoma conceptual que nos permite articular un pasaje exigido al plano de la relación estructura-acto: la noción de un narcisismo primario que se vincularía al ello y no al yo. Síntoma que nos parece indicar algo irresoluble en cierto terreno teórico ${ }^{14}$ : ¿qué puede querer decir un narcisismo que se define por el ello y no por el yo? Una mera contradicción en los términos, si nos atuviéramos a esa figura engañadora de un cuerpo que se autoinviste pulsionalmente antes de que el yo emerja en él como estructura diferenciada (según parece expresarlo la figura del tanque de almacenamiento que desliza Strachey: Cf. nota 12). Ahora bien, si al ello lo pensamos como una raíz de lo no realizado ${ }^{15}$ en la estructura, como aquello que debe advenir, dicha formulación del narcisismo primario cobra un sentido que aquí nos interesa especialmente: el ello denota desde esta óptica una pasividad constitutiva del cuerpo, un punto de precedencia estructural (insuprimible en tanto tal y no superable por ningún estadio) desde el que deberá pensarse el advenimiento, en acto, del sujeto: "Donde Ello era, Yo debo advenir". La alteridad constitutiva del ello puede ser también nombrada contingencia que habita al sujeto en su advenimiento. O también podríamos decir, contingencia necesaria para el advenimiento en acto del sujeto en la estructura. El ello, no independientemente del inconsciente sino en su engarce disyuntivo con él, es lo que nos muestra la ausencia de causa sui, el punto en que la causa está perdida: "yo no soy causa de mí mismo, ello, algo otro, me precede". No es que el ello esté exento de causa porque la colma de goce con los objetos pulsionales, como algunas lecturas parecen insinuar, se trata de otra cosa. En el ello queda registrado el agujero de la causa producto de su ensamble con el inconsciente, cuerpo pulsional que no encuentra su fundamento en sí mismo: aquí recupera su valor la impersonalidad del ello, enterrada por las lecturas que examinamos. El caldero está agujereado: ése es el lugar de la contingencia de la causa en el ello. El ello es la marca en la estructura de la no causa, de la causa perdida que no deja por eso de participar menos en la determinación de la estructura del sujeto. Si la del caldero agujereado es la metáfora de la contingencia en el ello, podemos contraponerla, con meros fines ilustrativos a la otra metáfora, la del gran reservorio de la libido, que se desliza fácilmente a un sustancialismo de las pulsiones; metáfora que a su vez se ancla en otra: la del caldero hirviente, sede de pulsiones desenfrenadas. 


\title{
4. El tratamiento del síntoma y la paradoja de la escisión y no separación entre yo y ello. De la causa a las consecuencias: la responsabilidad
}

\author{
"Para cualquier finalidad vital sería vano tratar de separar el yo del ello" \\ "He de experimentar entonces que esto, negado por mí, no sólo "está" en mí, \\ sino que también "actúa" ocasionalmente desde mi interior" \\ "No puede ser sino una parte de mi propio ser"
}

S. Freud

Para finalizar me gustaría detenerme brevemente en el modo en que se presenta en Freud la cuestión de la indivisibilidad en el seno mismo de lo tópico. Freud ya había dejado entrever cómo, en cierto plano, la división entre ello y yo podría parecer forzada; es lo que podemos leer en "La responsabilidad moral por el contenido de los sueños", donde manifiesta que prefiere dejarla a cargo del jurista: "El médico dejará para el jurista la tarea de establecer para los fines sociales una responsabilidad arbitrariamente restringida al yo metapsicológico" (2013b). En el tercer capítulo de "Inhibición, síntoma y angustia", encontramos además al síntoma abordado de una forma que permite ver el carácter performativo del acto en relación con la contingencia que lo constituye. Eso da otra densidad argumental y conceptual a la relación de unión-separación de ello y yo, tan degradada, como puede vislumbrase a partir de los visto en los puntos anteriores, al ser tratada en un mero registro tópico.

La separación del yo respecto del ello parece justificada; determinadas constelaciones nos la imponen. Pero, por otra parte, el yo es idéntico al ello, no es más que un sector del ello diferenciado en particular. Si conceptualmente oponemos ese fragmento al todo, o si se ha producido una efectiva bipartición entre ambos, se nos hará manifiesta la endeblez del yo. Pero si el yo permanece ligado con el ello, no es separable del ello, entonces muestra su fortaleza (1986b, p.93) ${ }^{16}$.

No rescato de esta cita el tema de la separación como de la ligazón elloyo en función de la endeblez o la fortaleza del yo; retengo solamente la idea de que puede ser pensado ya sea como ligado ya sea como separable del ello para que nos dirijamos a la significación más precisa que cobra en el discurrir de ese capítulo que tiene por eje a la noción de síntoma. La cuestión comienza a ser tratada en el sentido que intento destacar cuando va adquiriendo cierto relieve el problema del conflicto sintomático: 
Sería por completo injustificado representarse al yo y al ello como dos ejércitos diferentes" (Freud, 1986b, p.93)."Si el acto de la represión nos ha mostrado la fortaleza del yo, al mismo tiempo atestigua su impotencia y el carácter no influible de la moción pulsional singular del ello (Freud, 1986b, p.93).

Si la represión divide temporalmente al yo del ello, permanece enteramente cierto que, en cierta medida, no es escindible de él; lo que puede enunciarse de forma más simple al decirse que, por más que el yo funcione como desprendido del ello en la operación de la represión, los efectos del ello no dejan por eso de recaer menos sobre el yo: allí está el punto nodal que indica como es concebida por Freud la responsabilidad. Y aquí deberíamos tener en cuenta especialmente que ese yo no es recubierto con el término que designa la instancia imaginaria del moi sino que habría de ser inclinado hacia el je hablante, el que abre el horizonte de la pregunta por el lugar del sujeto en la estructura.

Lo que sucede en el ello no puede dejar de recaer por el yo, mostrándonos que la responsabilidad no podría suponer nunca una asunción heroica. Lo esencial de la cuestión podría verse tal vez más claramente si examináramos el plano de la ganancia del síntoma. De todas maneras, aquí sólo nos interesa precisar cómo se despeja, en la relación de fundición y partición entre ello y yo, el problema de la responsabilidad que unitariamente debe asumirse; y que en efecto se asume, tal como lo muestra Freud en "La responsabilidad moral por el contenido de los sueños": es un dato inobjetable de la experiencia clínica y de la vida cotidiana, queramos o no admitirlo, teórica o moralmente ${ }^{17}$. El conflicto no deja de articularse sintomáticamente, y la misma concepción del síntoma como extraterritorial es otro fuerte argumento que apoya la idea de que la división tópica del aparato en instancias psíquicas no se corresponde con un deslinde de responsabilidades ${ }^{18}$ (ni con sistemas que tienen voz y carácter propio, según la versión que Laplanche nos propone para las instancias de la nueva tópica; lo que nos parece conducir a una partición distante de esa unidad a la que Freud tiende para posicionar a la responsabilidad).

\section{Conclusiones.}

Hemos indagado a lo largo de este artículo los riesgos de la tópica cuando la representación espacial de los sistemas e instancias permanece estrechamente ligada a esquemas descriptivos, cuestión que fue problematizada tanto en relación con el uso laplanchiano del término antropomorfismo para la segunda tópica como de la metáfora del caldero hirviente de la que se vale Green para situar la tópica del ello y discutir el carácter gramatical que le otorga Lacan. En contraste con ello, pudimos ver como la explicación de las instancias por las identificaciones se 
enriquece y cobra un alcance argumental especial cuando se lo entrecruza con la posición del cuerpo pulsional (punto de partida para asociar el ello a lo tópico, pero que lleva a posiciones diametralmente distintas según la óptica de interrogación) en la estructura del sujeto. Esto nos permitió alcanzar una dimensión más fecunda de la instancia del ello. El intento por realzar este último aspecto es lo que nos ha llevado a producir un entrecruzamiento interrogativo de dos horizontes, el de las identificaciones y el de la ética del acto. En este sentido, se dejó marginalmente expuesto como la Spaltung freudiana del yo cobra un sentido especial cuando se la lee en función de la división del sujeto. La significación que consideramos debe ser otorgada a la noción de narcisismo primario a partir de los desarrollos de "El yo y el ello" nos permitió abordar la problematización del lugar del ello en la estructura para contrarrestar el impacto teórico que ha tenido en algunos autores esa figura descriptiva (y engañadora) del ello como tanque de almacenamiento. A partir de allí pudimos ver el sentido crucial de la vinculación con la sentencia freudiana con que Lacan tanto ha insistido: "Donde ello era, yo debo advenir", propulsando la inclinación del cuestionamiento del ello al terreno ético. Éste fue un punto de no menor relevancia en nuestro abordaje puesto que se intentó mostrar cómo se sitúan las nociones de pasividad y contingencia en relación con el lugar del ello en la estructura del sujeto. Pudimos dejar expuesta la manera en que creemos que este desplazamiento de acento anula las limitaciones de la metáfora espacial, recuperando así, desde otra perspectiva, una temprana aserción de Lacan respecto del lugar que debe darse a las instancias de la nueva tópica: el de exponer el descentramiento del sujeto. Si se coloca el énfasis en lugar del cuerpo en la estructura como punto de anclaje primordial en que se inserta el ello en relación con lo tópico, puede abrírselo, como vimos, a la perspectiva del acto. Todos estos aspectos nos parecieron de suma importancia teórica puesto que apuntan a recuperar las definiciones freudianas tendientes a situar al ello como algo incaptable, sólo susceptible de ser aprehendido "en forma negativa", en contra de cualquier positivización que quiera hacerse de esta instancia, de las cuales las encerradas en la mera localización tópica son las más desorientadas. Como contraposición a esto, pudimos problematizar ese lugar contingente del cuerpo en la estructura, mostrando que su sentido no es el de un lugar psíquico que posea pulsiones desenfrenadas, sino que expresa el registro de la alteridad en un cuerpo trabajado por las pulsiones (que se sitúan en una determinada relación con el gran Otro). Así es que pudimos situar cómo, en contra de la figura del tanque de almacenamiento, lo fundamental del ello reside en localizar el valor en la estructura de lo no realizado, tornando posible recuperar la impersonalidad del ello, para colocar el acento en la causa de un cuerpo pulsional que no encuentra su fundamento en sí mismo. La del "caldero agujereado" nos pareció ser la más válida de las metáforas propuestas (aunque sean todas ellas en cierto sentido limitadas) por permitir especificar el lugar de la contingencia de la causa en el ello. 
El artículo finaliza con una breve disquisición que implicó correr el foco del acento de la relación ello-estructura (y acto) al del problema de la partición y fusión entre yo y ello, donde se toma como eje del análisis la cuestión de la responsabilidad. El objetivo de este último acento reside en mostrar cómo la división entre ello y yo es más que nunca problemática cuando lo que está en cuestión son problemas éticos, lo que retorna insistentemente en la pregunta freudiana que sigue el hilo del tratamiento clínico del síntoma.

\section{Notas}

Esta noción, tal como la expone Laplanche, no debe conducirnos a pensar que se sitúa en la misma serie que ese antropomorfismo como modo de circunscribir la segunda tópica que Lagache rescata de las objeciones de que fue objeto por parte de Hartmann, Kris y Lowenstein (Lacan, J. [1960] (1975) "Observación sobre el informe de Daniel Lagache: "Psicoanálisis y estructura de la personalidad". Escritos II, Buenos Aires: Siglo XXI). El contexto de discusión que propongo es diferente, pues no se trata aquí de rescatar el antropomorfismo como rechazo de un modo fisiológico de concebir la segunda tópica, sino de insinuar cómo con esta noción Laplanche parece inclinarse a una versión de las identificaciones de tinte descriptiva, que desvía del problema del cuerpo como unidad escindida, fundamental para la distinción entre ello y yo que aquí acentuamos. Si bien este escrito de Lacan no fue tomado en cuenta en el desarrollo de este artículo, quisiera situar algunos aspectos del mismo que se sitúan en consonancia con lo que aquí exponemos: Por un lado, destacamos el hecho de que si en algún punto Lacan rescata los desarrollos de Lagache sobre el ello, es precisamente en el de haber encontrado que sobresale "su esfuerzo de situar allí al sujeto en su estructura" (Ibid., p.637). Por otro lado, es de relevancia el modo de abordaje de las pulsiones a partir de la distinción tópica ello-yo, que sintetizo tomando una breve cita que puede ser leída considerando los desarrollos con que avanzamos en este artículo: "Que las pulsiones por su parte ex-sistan, tal vez en eso consiste todo: en que no están en su lugar, que se proponen en esa Entstellung, en en esa de-posición..." (Ibid., p.641, destacado mío).

Lo que de manera un tanto aforística, pero no por ello menos contundente, se expresa con la formulación de que la división del sujeto es en acto y no podría nunca estar dada a priori.

Como caso extremo piénsese en la figura norteamericana del "ego autónomo" en el sentido de una esfera no conflictuada.

5 No podría limitarse por tanto a la figura de "daño imaginario" que Lacan propuso para la frustración.

En el sentido en que Lacan sostiene que ciertas derivaciones teóricas del psicoanálisis confluyen en su disolución en una psicología general. independizarse de los representantes; en Green la cuestión es más clara aún. 
Si se sigue lo avanzando por Lacan en La lógica del fantasma y El acto analítico puede verse que la tensión insuprimible entre ello e inconsciente como modalidad no tópica de articulación permite enfocar de otra manera la incidencia de las instancias en la clínica.

Digamos de paso que son recurrentes los rechazos de Lacan a cierta forma de pensar el narcisismo primario, tanto en el seminario La lógica del fantasma como El acto analítico, precisamente los seminarios en que más fuertemente traslada las "instancias" de la tópica hacia la dimensión de la ética del acto.

Llama la atención, especialmente aquí, esta calificación de "descriptivo", cuando se trata precisamente de presentar la tópica: como si la aserción permitiera insinuar algo defectuoso en el orden mismo de lo tópico. Lo interpretamos como un gesto que indicaría que lo tópico no dejaría nunca plenamente de lado cierto matiz descriptivo que es a la vez soporte y obstáculo del teorizar metapsicológico.

Esta cuestión podría iluminarse mejor si nos trasladáramos al problema de su articulación gramatical con el yo a partir del giro producido por Lacan. Me refiero a la articulación entre estructura y acto establecida en La lógica del fantasma y El acto analítico. A partir de allí se diferencian el no-yo del ello del no-yo del inconsciente en la perspectiva de una alternancia que excede el registro de la repartición tópica. ¿Por qué lo excede? Precisamente porque el punto de partida es la disyunción en acto; ello e inconsciente no se escinden ya tópicamente sino que entran temporalmente en disyunción.

Green nos propone al ello como mediación entre el cuerpo y el pensamiento. Sintetiza los desarrollos de Lacan de la siguiente manera: "el inconsciente está estructurado como un lenguaje; el Ello, pues en relación con el inconsciente es "todo lo que no es yo (je)", todo el resto de la estructura lógica como gramatical que es la esencia del Ello" ([1966/7], p.321). Una vez expuesto el planteo lacaniano, Green se dirige a Freud "para examinar la compatibilidad o incompatibilidad de la teoría lacaniana con la posición freudiana" (Idem.). Apoyándose en una afirmación freudiana de "El yo y el ello" (ligada a ese "otro cuantitativo" que no deviene conciente por intermedio de los representantes ligados al preconciente, sino que lo hace de forma directa), concluirá sobre la presencia de los afectos en el ello, que una mera combinatoria entre representaciones dejaría de lado.

No nos extraña que el punto de apoyatura para pensar el ello sea una figura, la del caldero hirviente de pulsiones desatadas que pujan en pos de una descarga. Tanto esta figura como el esquema del aparato que Freud propone son contraproducentes para pensar lo que el ello supone de novedoso en la llamada segunda tópica, o sea algo indiscernible en términos propiamente tópicos, según lo que aquí sostenemos.

14 Y que nos permite además sustraernos de los impasses de intentar explicar porqué el ello sería el gran reservorio de la libido: Cf. los esfuerzos malabarísticos de Strachey en su segundo apéndice a "El yo y el ello" de la Standart Edition por tornar coherente esta explicación, cuando, como lo muestra el mismo Strachey, Freud parece haberla rápidamente descartado, hablando en lo sucesivo indistintamente del ello o del yo como reservorio originario de la libido. Es precisamente la figura del ello como "tanque de almacenamiento" que propone Strachey la que queda más prendida de la faz descriptiva del ello por la vía de la localización espacial (1986, p.65).

Con esta noción reenvío a los planteos de Lacan del seminario Los cuatros conceptos fundamentales del psicoanálisis relativos al estatuto ético del inconsciente, donde sitúa al inconsciente como perteneciendo al orden de lo no realizado. 
Destacado del autor.

"La experiencia me demuestra que, no obstante, asumo esa responsabilidad, que de una u otra manera me veo compelido a asumirla" (Freud, 2013b, p.2895). "La misma conciencia moral es una formación reactiva frente a todo lo malo que percibe en el ello" (Idem.).

18 Es por eso que muchos de estos desarrollos de Freud van absolutamente en contra de la mala fe que algunos gustan objetarle al inconsciente psicoanalítico: "Y si, defendiéndome, digo que cuanto en mí es desconocido, inconsciente y reprimido no pertenece a mi yo, entonces me coloco fuera del terreno psicoanalítico" (Freud, 2013b, p.2895).

\section{Referencias bibliográficas}

Freud, Sigmund [1923] (1986a). El yo y el ello. En Obras Completas Vol. XIX, Buenos Aires: Amorrortu Editores.

[1926] (1986b) Inhibición, síntoma y angustia. En Obras Completas Vol XX. Buenos Aires: Amorrortu Editores.

[1932] (1986c). Conferencia 31: La descomposición de la personalidad psíquica. En Obras Completas Vol XXXII. Buenos Aires: Amorrortu Editores.

[1923] (2013a) El yo y el ello. En Obras completas Vol XIX, Buenos Aires: Siglo XXI.

[1925] (2013b) La responsabilidad moral por el contenido de los sueños. En Obras Completas Vol. XXI. Buenos Aires: Siglo XXI.

Green, André [1966/7]. Intervenciones en: Lacan, Jacques, La logique du fantasme, (seminario inédito), http://staferla.free.fr/S14/S14\%20LOGIQUE. pdf

Kuri, Carlos (2010). La identificación, Rosario: Homo Sapiens.

Lacan, Jacques [1954/5] (1978). Le moi dans la théorie de Freud et dans la technique de la psychanalyse. Paris: Seuil Points.

[1963/4] (1973). Les quatre concepts fondamentaux de la psychanalyse, Paris: Seuil Points. 
[1966/7] La logique du fantasme, (seminario inédito), http://staferla.free.fr/ S14/S14\%20LOGIQUE.pdf

Laplanche, Jean (1981). Problématiques IV, Paris: Presses Universitaires de France.

Strachey, James (1986) "Apéndice B. El gran reservorio de la libido". En Obras Completas Vol. XIX, Buenos Aires: Amorrortu Editores.

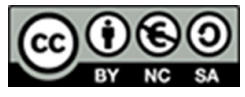

Esta obra está bajo una licencia de Creative Commons Reconocimiento

- NoComercial - CompartirIgual (by-nc-sa) 